Meta

Journal des traducteurs

Translators' Journal

\title{
Science, Translation and the Mangle: A Performative Conceptualization of Scientific Translation
}

\section{Maeve Olohan}

Volume 61, numéro hors-série, 2016

Sciences en traduction

Sciences in Translation

URI : https://id.erudit.org/iderudit/1038682ar

DOI : https://doi.org/10.7202/1038682ar

Aller au sommaire du numéro

Éditeur(s)

Les Presses de l’Université de Montréal

ISSN

0026-0452 (imprimé)

1492-1421 (numérique)

Découvrir la revue

Citer cet article

Olohan, M. (2016). Science, Translation and the Mangle: A Performative

Conceptualization of Scientific Translation. Meta, 61, 5-21.

https://doi.org/10.7202/1038682ar
Résumé de l'article

Dans un contexte où les approches historiques et sociologiques suscitent de plus en plus d'intérêt pour l'étude de la traduction scientifique, le présent article explore le potentiel heuristique du concept avancé par Andrew Pickering, selon lequel la pratique agit comme une tordeuse (mangle of practice ; Pickering $1992 ; 1993$; 1995 ; Pickering et Guzik 2008). Selon Pickering, la science est performative, de sorte qu'il faut rendre compte de l'interaction entre les agents humains et matériels engagés dans la pratique scientifique. Il est d'avis que les avancées scientifiques et technologiques émergent, au fil du temps, d'une dialectique entre résistance et accommodation, d'où la métaphore de la tordeuse. L'article présente les principaux arguments de Pickering, situe ceux-ci dans le contexte des études des sciences et technologies et explore ce qu'ils apportent à la traductologie, notamment aux études sur la pratique de la traduction. D’une part, ils permettent de mettre en évidence le rôle de la traduction dans l'exercice de la science et ouvrent la voie à l'étude de la traduction comme faisant partie intégrante des pratiques scientifiques. D'autre part, la perspective posthumaniste, ou décentrée, de Pickering permet de montrer l'interaction entre l'agent traducteur et la performativité matérielle parce qu'elle se concentre non seulement sur l'agent humain et l'agent matériel, mais aussi sur leur interaction. En conclusion, il est proposé que la traductologie prenne ce virage ontologique, lequel aiderait à mieux comprendre le rapport du traducteur aux outils, aux technologies et aux développements sociotechniques en traduction.
Ce document est protégé par la loi sur le droit d'auteur. L’utilisation des services d’Érudit (y compris la reproduction) est assujettie à sa politique d'utilisation que vous pouvez consulter en ligne.

https://apropos.erudit.org/fr/usagers/politique-dutilisation/ 


\title{
Science, Translation and the Mangle: A Performative Conceptualization of Scientific Translation
}

\author{
MAEVE OLOHAN \\ University of Manchester, Manchester, United Kingdom \\ maeve.olohan@manchester.ac.uk
}

\section{RÉSUMÉ}

Dans un contexte où les approches historiques et sociologiques suscitent de plus en plus d'intérêt pour l'étude de la traduction scientifique, le présent article explore le potentiel heuristique du concept avancé par Andrew Pickering, selon lequel la pratique agit comme une tordeuse (mangle of practice; Pickering 1992; 1993; 1995; Pickering et Guzik 2008). Selon Pickering, la science est performative, de sorte qu'il faut rendre compte de l'interaction entre les agents humains et matériels engagés dans la pratique scientifique. II est d'avis que les avancées scientifiques et technologiques émergent, au fil du temps, d'une dialectique entre résistance et accommodation, d'où la métaphore de la tordeuse. L'article présente les principaux arguments de Pickering, situe ceux-ci dans le contexte des études des sciences et technologies et explore ce qu'ils apportent à la traductologie, notamment aux études sur la pratique de la traduction. D'une part, ils permettent de mettre en évidence le rôle de la traduction dans l'exercice de la science et ouvrent la voie à l'étude de la traduction comme faisant partie intégrante des pratiques scientifiques. D'autre part, la perspective posthumaniste, ou décentrée, de Pickering permet de montrer l'interaction entre l'agent traducteur et la performativité matérielle parce qu'elle se concentre non seulement sur l'agent humain et l'agent matériel, mais aussi sur leur interaction. En conclusion, il est proposé que la traductologie prenne ce virage ontologique, lequel aiderait à mieux comprendre le rapport du traducteur aux outils, aux technologies et aux développements sociotechniques en traduction.

\begin{abstract}
Against a backdrop of growing interest in historical and sociological approaches to the translation of science, this paper explores the conceptual potential of Andrew Pickering's 'mangle of practice' (Pickering 1992; 1993; 1995; Pickering and Guzik 2008) as a sociological framework for research into the translation of science. Pickering's approach is situated within a performative idiom of science and seeks to account for the interplay of material and human agency in scientific practice. It sees scientific and technological advances as emerging temporally from a dialectic of resistance and accommodation, metaphorically the mangle of practice. This paper introduces the main tenets of Pickering's argument, contextualizing it within the field of science and technology studies. It then explores some of the implications of construing translation in these terms. Firstly, this conceptual approach helps to recognize the role of translation in the performance of science and to seek ways of studying translation practices as an integral component of scientific practices. Secondly, Pickering's posthumanist or decentred perspective focuses on both material and human agency and the interplay between them; a similar approach to the study of translation would foreground the interaction between translator agency and material performativity in studies of translation practices. I conclude with proposals for adopting this ontological shift in translation studies, where it may have the potential to enhance our understanding of translation practices, in particular in relation to tools, technologies and sociotechnical developments in translation.
\end{abstract}




\section{MOTS-CLÉS/KEYWORDS}

études des sciences et technologies, pratique de la traduction scientifique, agent humain, performativité matérielle, histoire des sciences

science and technology studies, scientific translation practice, human agency, material performativity, history of science

\section{Introduction}

In 1837 a publication appeared in London, called Scientific Memoirs, Selected from the Transactions of Foreign Academies of Science and Learned Societies and from Foreign Journals. This was Volume 1 of a periodical, published in five volumes, each comprising either 4 or 5 parts, between 1837 and 1852. At an average of 680 pages per volume, the endeavour produced some 3,400 pages of scientific translation into English, mostly from German and French. The periodical was set up in London by Richard Taylor, one of the founders of the present-day Taylor and Francis publishing company. Taylor was a publisher and printer, as well as an editor of scientific materials, including the Philosophical Magazine. Coming to the conclusion during the $1830 \mathrm{~s}$ that there was a need for more translation of scientific articles and memoirs from other languages into English, Taylor founded Scientific Memoirs for this purpose.

From my perspective as a translation scholar interested in scientific translation, this seemed to be an initiative worth studying because it comprised a substantial amount of translation effort, during the period known as "the age of science" (Knight 1986) and at a juncture when science lacked a lingua franca and women translated as a way of being involved in scientific activities. Apart from two or three pages in a biography of the Taylor and Francis publishing house (Brock and Meadows 1998), this publication had not been studied before, and had not been considered in terms of its translational significance. I set out to examine the periodical volumes themselves as well as paratexts, translator notes, and correspondence and other papers in archives, writing an account of Taylor's Scientific Memoirs which was published in the British Journal for the History of Science (Olohan 2014), focusing on Taylor's conception of the utility of translation. Taylor thought it was necessary for scientific progress, so that British scientists would not waste time duplicating work already done elsewhere, and that there was not enough space in existing periodicals for anything more than occasional translations. I looked at how Taylor exercised a strong gate-keeping function in the choice of material to be translated and also a localizing function when adding editorial or translator notes to relate the scientific material more explicitly to work with which the British readers would be familiar. I reflected, in sociological terms, on Taylor's mode of editorship, and his very specific and personal role in launching the periodical and ensuring its continuation for 15 years, despite it being barely commercially viable through most of that time. That discussion was preceded by a paper (Olohan 2012) in a special issue of The Translator dedicated to non-professionals translating and interpreting, in which I sought to explain the motivations of volunteer translators and volunteer reviewers, men and women, for Scientific Memoirs, drawing on behavioural economic models of pure and impure altruism, so that volunteer translation could be related to the volunteering of other goods or services, as researched by other disciplines. 
Both of these accounts were centred on people, either Taylor or the translators, reviewers and other scientists supporting his endeavour. Certainly, historians of science are increasingly interested in the history of publishing and the "technicians of print" (Jardine 2000; Topham 2004), while translation scholars are increasingly interested in agency of translators and in volunteer translators (Milton and Bandia 2009; Kinnunen and Koskinen 2010; Pérez González 2010; McDonough Dolmaya 2012; Pérez González 2013). However, one could argue that both papers, in focusing so centrally on human agency, paid too little attention to other factors which also contribute to explaining this episode in scientific translation publishing. I would therefore like to explore here how the study of such translation activities would be further enlightened by an approach which is grounded in science and technology studies and which takes greater account of material as well as human agency, and approaches scientific translation as a form of sociotechnical practice. My intention in this paper that was presented at the 2013 CATS conference is to introduce some main strands of thinking and key concepts from the field known as science and technology studies, in particular the work of sociologist Andrew Pickering, and to argue for the usefulness or productivity of these ideas for the study of translation, and perhaps particularly for studying the translation of science.

Section 2 outlines, in brief, key developments in science and technology studies in order to contextualize Pickering's conceptual approach and "the mangle of practice," the main tenets of which are discussed in Section 3. Section 4 then seeks to reconceptualize aspects of scientific translation, and translation practice more generally, in those terms and to illustrate this using the historical case study of scientific translation publishing. The paper concludes with some proposals for research agendas prompted by this reconceptualization.

\section{Science and technology studies}

Translation studies has drawn increasingly on social theories to explain translation and the activities of translators. Pierre Bourdieu's field theory has been the most influential of these theories so far (Simeoni 1998; Gouanvic 2005; Inghilleri 2005), with a smaller number of translation scholars influenced by other social theorists, including Niklas Luhmann (Hermans 2007; Tyulenev 2012) and Bruno Latour (Buzelin 2005; 2007). In studying scientific translation in more detail, a first useful step is to explore different understandings of science, so that a characterization of scientific translation can draw on a characterization of science. Obvious sources include the fields of the philosophy of science, the sociology of science, the history of science, and the rhetoric of science. Of particular interest for this paper is a branch of the sociology of science which is now known as science and technology studies, or STS. Some key contributions in the development of STS are traced here, in broad terms, in order to contextualize Andrew Pickering's approach, which is the focus of Section 3 (see Sismondo 2010 for a more comprehensive introduction to STS).

Many narratives of the development of the sociology of science start around and after World War II, with Robert K. Merton, often considered to be the founding father of the sociology of science. Indeed, he approached scientific practice as a social activity, though within the prevailing positivist framework. Among other aspects, Merton 
examined motivations for doing science, and ways in which scientific contributions are evaluated and the ways in which scientific excellence is rewarded (Merton 1973). In hindsight, Merton's approach might be described as a sociology of scientists, rather than a sociology of science. A second major contribution may be seen in the work of Thomas Kuhn on the nature of scientific communities and the development of scientific fields. In the seminal book, The Structure of Scientific Revolutions (1962), he argued that science does not progress by accretion, but rather through revolutionary processes in which one paradigm is rejected and replaced by an incompatible new one. Thus, science develops from the pre-paradigm phase (characterized by competing schools and lack of evidence of progress) to mature science which is characterized by periods of a common paradigm - termed normal science-and periods of scientific revolution, termed paradigm change, or gestalt-switch, brought about by crisis and anomaly. The puzzle-solving nature of scientific development is reflected in features which include the relative scarcity of competing schools in the developed sciences, the exclusivity of the scientific community as audience for the community's work, the relative insulation of the scientist from society, and the nature of scientific education and training (Kuhn 1970: 208-209).

Work in the field of the sociology of science gained momentum in the late 1950s and the 1960s, coinciding with the space race and the US government's growing perception of science as a social problem (Storer 1973: xxiv). Studies focused in particular on scientists in organizations, the communication of science and the organization of scientific knowledge. What has been dubbed the "second wave of science studies" (Collins and Evans 2002) emerged through the 1970s, particularly in Edinburgh, through what was called the strong programme in the sociology of scientific knowledge, or SSK. A key idea in SSK was that society exerted an influence, not just on the choice of research questions tackled by science and the way in which science is organized institutionally, but on the outcome of the scientific work itself. Thus, SSK scholars believed that society was "a constituent of knowledge," not merely the "precondition of science" (Bloor 2007: 220-221). SSK sought causal explanation for the establishment of scientific knowledge, with an emphasis on social factors in the explanation. SSK drew on interest theory, ascribing interests to those involved in science and relating scientific beliefs to those interests. ${ }^{1}$

Since the 1970s STS has moved beyond SSK's focus on structures and interests, and attention has shifted to agency and to studying the practices and activities of science and technology in their own right. ${ }^{2}$ From the 1970s and into the 1980s, the social construction of scientific knowledge was investigated ethnographically through studies in which scientists were observed in their laboratory settings. This work, begun by Bruno Latour and Steve Woolgar (1979; 1986), entailed a shift from thinking about science as knowledge to considering science as practice; the production of scientific knowledge was now being studied at the site of production (usually the laboratory), and it was felt that observation would provide rich data on how scientists worked and interacted. Through their workplace observations, Latour and colleagues concluded that scientific knowledge was constructed through locally embedded practices in the laboratory and through collaboration and negotiation between scientists. ${ }^{3}$

While Latour and others focused on the construction of knowledge in the laboratory, i.e., the accomplishment of knowledge claims through scientists' interaction, 
Knorr Cetina was interested in studying what she terms "epistemic cultures," i.e., "cultures of creating and warranting knowledge" (Knorr Cetina 2007: 363). She shifted the focus of empirical investigations from knowledge construction (knowledge as practice) to the machineries of knowledge construction, i.e., the mechanisms which make up how we know what we know (Knorr Cetina 1999: 2-3). Those knowledge processes - the cultures which produce and sustain knowledge-are, she argued, more diverse than was seen in the earlier laboratory studies which lacked this cultural perspective, because they usually focused on one area of knowledge. She hypothesized diversity in terms of the influences of national cultures on how science is done and also diversity in terms of the differences between knowledge cultures in different branches or areas of science (Knorr Cetina 2001: 8235). Through fieldwork Knorr Cetina sought to determine who or what are the agents in scientific practice, what are the objects of knowledge, where are the places of knowledge and what are the prescribed ways in which objects of knowledge are approached in research (Knorr Cetina 2007: 366). She found these epistemic cultures to be diverse and thus could reject the assumption of the unity of science.

While Knorr Cetina challenged the notion of the unity of science, Donna Haraway and others challenged the notion of science as value-neutral, by approaching science from alternative standpoints, including feminist perspectives (Fox Keller 1985; Haraway 1988). Haraway, in particular, argued that feminism should seek to shape science and technology around its interests and she proposed the notion of the cyborg (Haraway 1991) to characterize the blurring of the traditional boundaries between human and machine in STS. This perspective, which rejects the idea that the human is at the centre of science, is described as posthumanist.

Bruno Latour, mentioned above for his earlier laboratory studies with Steve Woolgar, remains a key figure in the study of science and society, and present-day STS draws extensively on much of his work. Together with Michel Callon and John Law, Latour developed actor-network theory (ANT) (Law 1992; Latour 2005), conceiving of scientists as constructing heterogeneous networks combining different elements of material and social worlds which shape one another in a process of coconstruction (Sismondo 2010: 65). Latour's work is particularly significant for STS, not least because he rejects the dichotomies and binaries that prevailed in much of the earlier work on the sociology of science and that continue to be observed between science and technology studies and mainstream sociology. For Latour, science/technology and society are not separate entities but are connected within a network of technoscience, and he is interested in studying the trail of connections or associations between heterogeneous elements and the aggregates of those elements, which are stabilized by actors, both human and non-human.

\section{The mangle of practice}

Andrew Pickering's academic background was in physics and his first major contribution to STS was a history of particle physics, Constructing Quarks (1984), in which he analyzed how the practices of particle physicists constructed a new view of matter, the quark view, which he also called the new physics. In line with Kuhn's (1962) notions of paradigm and paradigm change in science, Pickering (1984) showed the incommensurability of the two paradigms of the new physics and the old physics; 
they were very different in many respects, including the kinds of experiments and instruments used.

This attention to experiments and material objects in the performance of science played an important part in Pickering's subsequent work. In The Mangle of Practice (1995), he lays out the tenets of his conceptualization and approach to practice and agency. Pickering sees his account as the mirror image of the conventional scientific and realist-oriented accounts. Like Latour and his ANT colleagues, Pickering highlights what he describes as the "multiplicity, patchiness, and heterogeneity of the space in which scientists work" (Pickering 1992: 7-8). Pickering is interested in realtime understanding of science as practice or performance: he argues that "what scientists do is just as important as the knowledge they produce" (Pickering 1992: 7-8). Like Latour, Pickering's conceptualization of science or technoscience moves us away from dualisms of realism and relativism, human and nonhuman, science and society. His focus is on flux and performance.

Pickering's (1995) main concern is to account for the emergence of science and technology and, in this emergence, he gives a prominent role to non-human, i.e., material, agency. He argues that much of past studies of the history, philosophy or sociology of science neglected experiments, material objects and material agency, and that this material agency is vital for our understanding of science. However, unlike Latour and ANT, Pickering treats human and material agency differently, ascribing intentionality to human agents but not to material objects. Other scholars, like Orlikowski (2005), helpfully make a terminological differentiation by referring to human agency on the one hand and material performativity on the other. In Pickering's terms, the interplay of human and material agency as they interactively stabilize each other is described as a dance of agency, also likened to tuning a car radio (though presumably the image evoked here is of an analogue radio operated via a tuning knob).

In Pickering's view, the process by which science and technology emerge is like laundry being wrung through a mangle, another image requiring some familiarity with older forms of technology. The mangle of practice is the label given to the dialectic of resistance and accommodation which is brought to bear on scientific and technological advances. Thus, science is a performative give-and-take, back-andforth, in the pursuit of a scientific goal. Resistance can be offered by any entity, including material objects; this can be observed in many scientific experiments in which apparatus and other material objects offer resistance to the smooth running of the experiment or to the gathering or analysis of relevant data. The scientist responds by accommodation, to overcome or avoid resistances, and so practice proceeds, moving backwards and forwards between resistances and accommodations.

The metaphor of the mangle usefully conjures up the unpredictability of the outcome of this dialectic of resistance and accommodation. The mangling process is described as temporally emergent, i.e., the contours of human or material agency are not decisively known in advance but emerge in the course of scientific practice, just as the mangled laundry will have a different and unpredictable shape as it emerges from the mangle (e.g., Pickering 1995). It is not possible to predict in advance where resistances will be encountered and what will play a constitutive role in the development of the science or the technology, or any course of events. In other words, the resistances emerge in the real time of practice. 
Another characteristic of the mangle is what Pickering describes as posthumanist. Like Haraway's cyborg (1991), Pickering's use of the term posthumanist signals that the analysis of practice is decentred; this means that it does not foreground either human agency or material agency, but looks at how human agency is intertwined with non-human/material agency and how the two are mutually productive or constitutive of one another, in an open-ended interplay. In later work (e.g., Pickering 2010), he reformulates posthumanist as non-dualist, to reflect this rejection of the human/non-human dualism.

Finally, Pickering contrasts these two idioms for thinking about science, the representational idiom and the performative idiom. The representational idiom sees science as an activity that seeks to represent nature, to produce knowledge that maps onto how the world really is, with scientists as "disembodied intellects making knowledge in a field of facts and observations" (Pickering 1995: 6). But, he argues, science is not just about representation. An alternative way of thinking is that the world is filled, not with facts but with agency:

The world is continually doing things. [...] Much of everyday life has the character of coping with material agency. [...] We should see science as a continuation and extension of the business of coping with material agency. Machines are central to how scientists do this [...] Scientists, as human agents, manoeuver in a field of material agency, constructing machines that variously capture, seduce, download, recruit, enrol or materialize that agency, taming and domesticating it, putting it at our service, often in the accomplishment of tasks that are simply beyond the capacities of naked human minds and bodies, individually or collectively. (Pickering 1995: 6)

This, then, is the basis for a performative view of science. Science is studied as it emerges in practice, in real-time, not as "a body of representations of reality" (Pickering 2010: 19). In other words, science is understood "as a mode of performative engagement with the world" (Pickering 2010: 19). One of the examples that Pickering uses to illustrate the interplay of human and non-human agency, the dance of agency, and the resistances and accommodations of the mangle is the Mississippi and its levees and weirs, i.e., the resistances and accommodations between the river and the efforts by the US Army Corps over the past 150 years to control its course (Pickering 2008a).

\section{Translation practice and the mangle}

The translation of science is an activity which has been relatively neglected by translation studies over the years. In the early days of translation studies, and translation pedagogy in particular, there may have been a tendency to approach scientific translation in a positivist framework, perhaps reflecting a view of the unity of science, focusing on referential functions of scientific language, not really recognizing that scientific ideas are constructed by scientists in certain ways to achieve certain rhetorical functions, and indeed that there are many different sciences, with different discourses for different addressees and different practices. The balance is being redressed by recent contributions to translation, including this journal issue (see also contributions in Olohan and Salama-Carr 2011).

So what is the relevance of this emergent, decentred conceptualization of scientific practice for the study of scientific translation? Pickering first applies the 
conceptualization of the mangle in a set of four case studies relating to scientific discovery and technological innovation (Pickering 1995). However, he has also emphasized in more recent work that it can be a productive approach for other subject areas and he encourages all scholars to take an interest in decentred and emergent processes (Pickering 2008b: vi, viii). As a result, the mangle has been applied to a range of situations and dances of agency, beyond the history of science. An illustrative set of studies is seen in Pickering and Guzik's (2008) collected volume of mangleinspired research on software development, large-scale pig farming, combating domestic violence in the US, Australian bush fires and national identity, traditional Chinese medicine, conservation and environmental management, and information systems research. I first introduced the mangle in translation studies by attempting to study some of the interplay between translators and translation technologies (Olohan 2011). I would like to continue to explore here some implications of adopting a mangle-like approach to translation and in translation studies.

The first implication is a re-appraisal of translation in the study of science. The mangle approach and the study of performance and of practice can help us to better accommodate the role of translation in the performance of science and to seek ways of studying translation as an integral component of scientific practice, past or present. Studies of the history of science, conducted by historians of science, for example, tend to disregard or downplay the role of translation or consider it only in a philological sense. Historians of science often acknowledge that translation has happened but may not recognize the socio-cultural contingency of translation and its importance as a form of intercultural contact. This lack of attention paid to the practice of translation in the history of science seems to imply a taking for granted of relations of equivalence between source and target texts, a certain transparency of transfer operations, a representational idiom of both science and translation.

By contrast, pursuing the mangle perspective on scientific practice encourages us to see translation practice (as any other communication practice) as interconnected with practice and to study it in that light. This would mean paying greater attention to the practices of translating and of producing, publishing and disseminating translations, and focusing more on the interplay between human agents and the material conditions of that production, with acknowledgement also of the emergent nature of translations through a dialectic of resistance and accommodation. Just as the multiplicity, disunity and heterogeneity of science becomes clear in STS, that multiplicity, disunity and heterogeneity could be better reflected in studies of the translation of science. That means recognizing the multiplicity of purposes, functions and readerships of multiple scientific discourses (e.g., popular science vs. professional science), but also recognizing how translations, as material and conceptual objects, figure in the practices of science, how translations perform science. Such research projects may well require the combined linguistic and intercultural expertise of translation scholars with the scientific and discipline-specific expertise of historians of science.

An example may be taken from Taylor's Scientific Memoirs. Perhaps the most well-known translation published in these volumes was of a paper by the Italian military engineer and mathematician, Luigi Federico Menabrae, about Charles Babbage's Analytical Engine. Babbage had received many years of financial support in Britain for his previous venture, the Difference Engine, designed to be an intelli- 
gent calculating machine, but a failure to deliver more than a small prototype meant that funding for the Difference Engine was suspended and Babbage was unlikely to receive support for the new Analytical Engine in Britain (Green 2001: 136). In 1840 Babbage presented his ideas and drawings to the Academy of Turin, expecting the eminent Baron Plana to write an account of the presentation which could be of use to Babbage as he continued to press the British government for funding (Green 2001: 134). Plana passed the task of writing the report to a junior colleague, Menabrae. Although somewhat disappointed, Babbage expressed himself happy enough with Menabrae's endorsing account (Huskey and Huskey 1980: 310) which was written in French and published in the Bibliothèque Universelle de Genève in October 1842.

Taylor, encouraged by Charles Wheatstone, arranged for Ada Lovelace to translate Menabrae's paper into English so that it could be published in Scientific Memoirs. Lovelace, daughter of Lord Byron, was well-versed in mathematics and closely acquainted with and supportive of Babbage's work, having first observed the Difference Engine in operation in 1833 (Huskey and Huskey 1980: 300). She was able to correct some of Menabrae's misunderstandings (Fuegi and Francis 2003) and, prompted by Babbage, embarked on writing a series of Notes to accompany the translation. The Notes eventually became three times as long as the translation. Lovelace's notes are regarded as more insightful than Babbage's writings and as the best textual exposition of the Analytical Engine (Toole 1996). Indeed, Green, in a discussion of Babbage's and Lovelace's contribution to cognitive science and the importance of the notes, refers to the "oft-forgotten article to which they were appended" (Green 2001: 133). Lovelace signed the notes with her initials, though not the translation; in any case it was well-known in scientific and publishing circles that both were her work.

The correspondence between Lovelace and Babbage reveals something of the process of writing the notes, as letters flew back and forth between them on an extremely frequent basis, sometimes several in one day, by post and personal messenger, discussing and clarifying many points for the notes over a period of months (Fuegi and Francis 2003). They also met regularly to discuss the notes. From the correspondence in particular, we can see how Lovelace clarified and extended many of Babbage's original ideas, illustrating and applying them, and enabling him to come to realizations which he had not had hitherto. Although Lovelace was exasperated by Babbage's lack of organization, their main disagreement came towards the end of the writing process when Babbage wanted to include alongside the notes a supplementary text complaining about his treatment by those who had refused to fund him, described by Lovelace as a "diatribe" and likely to undo her valiant attempts to help him to find renewed favour for his ideas (Fuegi and Francis 2003: 22). Lovelace objected to the inclusion of this text, and Taylor deferred to Lovelace as author when Babbage then tried to have the publication withdrawn, so that article and notes were indeed published, and Babbage was forced to publish his diatribe elsewhere. When the article and notes were favourably received, Babbage reconciled with Lovelace, signing a letter to her "Ever my fair Interpretess, Your faithful slave C. Babbage" (Fuegi and Francis 2003: 24).

This example serves to illustrate how the processes and practices of translation and writing were integral to the development of scientific ideas and how those ideas themselves were temporally emergent and gradually stabilized. It also underlines the 
importance of material objects in those processes and practices, from the working prototype of the Difference Engine which sparked Lovelace's interest in Babbage's work, to the physical drawings on the basis of which Babbage and Lovelace developed an understanding and explanation of the Analytical Engine (which was never built), to the limitations of the printing machinery of the time which required Lovelace to be physically present to supervise part of the printing process (Fuegi and Francis 2003: 23), to the accumulation of correspondence between Lovelace and Babbage, often written hastily and conveying excitement and urgency, reflecting the resistances and accommodations of this scientific practice.

Extending the discussion of implications for translation studies of an analytical approach which foregrounds translation practice, we return to one of Pickering's scientific examples. It concerns the controversy between Morpurgo and Fairbank, two physicists who performed experiments in research teams in the 1960s and 1970s to look for isolated quarks. Fairbank believed he had evidence for the existence of quarks; Morpurgo believed he had evidence for the non-existence of quarks. They had similar resources and goals but different trajectories. Pickering explains how, through the second half of the 1970s, similar material procedures, understood in terms of very similar interpretive accounts, managed to sustain diametrically opposed accounts of the material world, i.e., quarks for Fairbank, no quarks for Morpurgo. In mangle terms, this is explained simply by the contingencies of resistance and accommodation working out differently in the two instances. The same perspective could be applied to translations. We know that two translators translating the same source text are unlikely to translate it in the same way, thus producing outputs which differ in some respects. Research efforts in translation studies often seek to account for such differences in translation approaches and products, particularly when the texts are considered culturally important and they have been retranslated, and the explanation is often grounded in linguistic or socio-cultural factors. The mangle approach encourages us to focus on the contingencies of resistances and accommodations as a source of explanation for the differences between translation products, thus shifting away from accounts which foreground either human interests or textual features. It prompts instead consideration of translation as sociomaterial or sociotechnical practice, where attention is given to the ways in which the social and the technical are 'tuned' to one another to stabilize the translation process and product. So, unlike much of translation studies that has gone before, the primary or exclusive focus of research would not be the translation product, nor the translation process in cognitive terms, nor the translator. It is instead the interaction between human agency (of the translator and others) and material performativity. As mentioned above, a first attempt at doing this was the study of the resistances and accommodations of translators as they adopted a new version of a translation memory tool (Olohan 2011), showing that this conceptualization may have the potential to enhance our understanding of tools, technologies, crowdsourcing and other sociotechnical developments in translation.

Returning to our starting point and Scientific Memoirs, the mangle perspective would expand the study of this scientific publishing endeavour beyond that of Taylor's personal convictions or the motives of translators and into the realms of Taylor's and other actors' interactions with material objects. One aspect, among others that could be focused on, is the physical movement of books, papers and letters. In 1838, Taylor 
gave evidence before a Parliamentary select committee on postage which was tasked with examining the issue of postage costs in advance of the introduction of the penny post in 1940 (Anonymous 1838). When questioned, Taylor made the point that speed of diffusion was important when it came to new scientific discoveries and that numerous discoveries in Britain came late, having been already known in Germany for 10 or more years (Anonymous 1838). He argued that the speedy diffusion could be achieved through exchange of journals, but very few journals were taken in England because of the expense and difficulties of receiving them, and postage was a great financial burden on scientific publishers. Taylor attributed the failure of most scientific journals to postage costs, which pushed up sales costs. Costs were initially incurred in communicating with authors and in the transmission of papers and perhaps drawings, then in the correspondence about details before the paper went to press and the subsequent dispatching of proofs by editor or printer to the author. Significant costs were also incurred by publishers when people who had been entrusted to carry packets by hand from abroad found their packets seized by customs officers and placed in the postal system, thus requiring the editor to pay a substantial sum for their carriage on arrival, regardless of whether they found the material to be of merit (Anonymous 1838).

Taylor was convinced that a large reduction in the cost of postage would facilitate wider and more immediate communication of science within the UK but also from all parts of the world, thus ensuring that new discoveries would be communicated faster and more easily than was the case. He saw great merit in editors of journals exchanging their publications and noted that papers which appeared in British scientific journals were quickly published in France, Italy, Germany and the US once the British journals reached those shores. However, this interchange between editors was often thwarted by the expense and uncertainty of transmission.

Thus, we can note that Taylor's goal was to make his audience aware of new scientific discoveries and to furnish them with translations, but for this to happen he needed to be in receipt of the latest journals from continental Europe. However, there was resistance to this goal in the shape of lack of cheap, reliable postal services. Taylor accommodated by using those who travelled abroad, e.g., Foreign Office officials or members of parliament, to have the materials hand-delivered from and to other countries, free of charge but not always reliably. But the hand-delivered items met further resistances, often being confiscated from their carriers by customs, and then placed into the postal system, so that Taylor would end up having to pay more for them, sometimes when the material was worthless to him (Anonymous 1838).

Similarly the lack of a cheap and reliable postal service impinged on Taylor's dealings with authors and translators. He accommodated this resistance by not sending out revises, or sometimes no second proof or even no first proof, although this was not a desirable state of affairs. He wanted to be in constant communication with authors and to be able to allow them to make revisions to improve their paper, even at the printing stage. Authors, when sending their proofs or parcels from the country, by coach parcel or by private hand, would also take advantage of the opportunity to include numerous private letters from themselves and their friends and neighbours for their correspondents in London, which Taylor would then send to their final destination by hand or by the twopenny-post; this was a daily occurrence. While an 
accommodation to the resistances of the postal system, this also placed Taylor at the centre of communication between scientists, an advantageous position for a scientific publisher.

It was too costly to send out circulars or prospectuses for publications by post so Taylor accommodated by sewing advertisements into printed volumes of journals. But this meant that they might not be seen by their intended audience. It was also common practice for scientific institutions to circulate notices to their members via local treasurers, who would undertake to deliver them by hand in a locality, rather than use the postal system. These were among the areas where Taylor saw the potential for increased use of the postal system if it were cheap and reliable.

These brief examples offer a glimpse into the interplay between publishers, printers, authors and translators and the material objects of the journals, papers, proofs, advertisements and correspondence, providing both resistances and accommodations to the goal of scientific communication and the production of publications, including translations. Similar attention could be paid to printing practices, including the introduction of various printing machinery and the challenges of producing plate illustrations to accompany scientific papers, to name but a couple of material aspects of those publishing practices.

\section{Towards a mangle-inspired research agenda for translation studies}

In this final section, I would like to explore some of the prospects for empirical research into translation within this performative idiom. The mangle can be seen as a new ontology, an alternative view of science and the world. The conventional ontology of modern science relies on the dualism of people and things and the predictable nature of science; it tells us that we humans can know and understand the world and we can control, reconfigure and dominate it. Pickering's alternative ontology highlights unknowability and open-ended emergence in the world; it views the world as a place of becoming, of revealing, of open-endedness. While Pickering suggests that it could be useful to have, not one, but two ontologies of understanding the world, he believes that the second one, the mangle ontology, is more applicable to our world (Pickering 2008a). In his study of the history of British cybernetics (2010), Pickering also illustrates how this ontological shift has an impact on research agendas, from a concern with observers' personal responsibility for their knowledge claims to an understanding of systems as unknowable, or extremely complex, and as evolving and becoming in unpredictable ways (Pickering 2010: 33).

It may be argued that the traditional epistemological basis of translation studies results in the performative materiality of the field being ignored, and machines, artifacts and instruments being marginalized. By contrast, a more performative perspective would prompt studies of translation practices which integrate material performativity, for example by drawing on workplace studies, and adopting an ethnographic methodology or framework. Following Hammersley and Atkinson (2007), among others, and situating ethnography in relation to its roots in anthropology, it can be understood as encompassing various research methods or approaches which share a set of common features or core principles, including the fact that it is research in the field, studying people and actions in their everyday contexts, as opposed to experimental studies under controlled conditions. As seen above, Latour and 
Woolgar (1979), Knorr Cetina (1999), Traweek (1988) and others were conducting ethnographic research in science labs in the 1970s and 1980s. At the end of the 1990s, Brian Mossop (2000) proposed a research project to address the "curious gap in our knowledge about translation," referring to the lack of systematic observations of "how professional translators proceed when they translate" (Mossop 2000: 40). Mossop's proposal was to carry out such observations on a large scale and in conjunction with interviews or questionnaires and assessment of the quality of translators' outputs. In his view, the main impediment to such research up to that point lay in the characteristics of translation studies and translation scholars. Translation studies, he argued, prioritized translation product over the translator and the translation process (with some exceptions), and translation pedagogy focused on training students rather than on continuing professional development. Moreover, university-based academics were distanced from the professional world of translation and their work continued to be predominantly influenced by or oriented towards linguistics and literary studies (Mossop 2000: 40).

Assessing the extent to which researchers have addressed Mossop's proposal, either implicitly or explicitly, it can be noted that translation studies now benefits from a number of studies based on systematic observations of specific workplaces. These include Kaisa Koskinen's (2008) study in the Finnish translation unit of the European Commission's translation service, Mossop's study of the Canadian Translation Bureau (e.g., 2006) and Hélène Buzelin's (2006; 2007) study of literary translation production by independent publishers in Québec, following the process ethnographically from the negotiation of translation rights through to the launch and marketing of the translation. But these remain relatively small in number and scope. In particular there have been few studies which focus on the translation activities most prevalent today, not in international or governmental institutions, or in literary translation, but in the commercial sector, where translators work freelance for translation agencies on texts from predominantly technical and commercial domains. Recent interesting contributions in that sector include Karamanis, Luz et al. (2011) and LeBlanc (2013). At the time of writing in 2013, work has also begun in a research project at the University of Manchester, using an explicitly ethnographic approach and drawing on the longer tradition of workplace studies (see Luff, Hindmarsh et al. 2000) and more recent studies of CSCW-computer-supported collaborative work-to study the interplay between human agency and material performativity in translation project management (see Olohan and Davitti 2015).

\section{Conclusion}

In conclusion, there remains enormous potential for study of translation practices in the commercial environment. STS and, in particular, Pickering's mangle direct our attention to those practices in two key ways. Firstly, for those interested in studying the role of translation in science, the mangle helps us to highlight the practice of translation as part of, and as integral to, the performing of science and technoscience, rather than something to be considered separately and predominantly philologically. Secondly, it provides us with a framework for studying translation practice in a performative idiom, an approach which examines resistances and accommodations, interplay of human and material or machinic agency, which are temporally emergent 
and not decisively known in advance. Focusing on the sociotechnical practices of translation helps us to understand the contingencies of translation practices and their temporal emergence through those dances of agency. As Pickering (2003: 108) notes, rock musicians of the 1960s like Jimi Hendrix or Pink Floyd came up with new ways of holding and playing the guitar that were different from their predecessors, like the Beatles. These were new human/machine couplings prompted by the artists' desire to do it differently, to try different ways, to experiment, to see what happened. There was an awareness of becoming, of openendedness, and what emerged were novel and interesting sounds. In studying translators and their machine couplings, their dances of agency, through the ontology of the mangle, we might also develop our awareness of emergence, openendedness and becoming, through which translations and translation practices may be revealed in novel and interesting ways.

\section{NOTES}

1. This perspective was underpinned by Quine's thesis on underdetermination of theory by data; that is to say, if scientific theory is underdetermined by evidence or data, there may be multiple hypotheses or theories which are compatible with the data. The choice of theory is then determined, not by data, but by something else; SSK scholars argued that the choice of theory is motivated by interests and social factors.

2. Pickering notes, for example, that "SSK simply does not offer us the conceptual apparatus needed to catch up the richness of the doing of science" (Pickering 1992: 5) and he argues that there seems to be "no warrant for assigning causal priority to the social in understanding scientific practice and culture" (Pickering 1992: 14).

3. Although entailing a significant methodological shift away from the study of what scientists say towards the study of what scientists do (Zammito 2007: 805), it can be noted that this work has also been criticized for focusing rather heavily on the study of the texts and representations produced and less on the scientists' work routines and skills (Shapin 1988: 546).

\section{REFERENCES}

Anonymous (1838): First Report from the Select Committee of the House of Commons on Postage; together with the Minutes of Evidence and Appendix. The Sessional Papers Printed by Order of The House of Lords, or Presented by Royal Command, in the Session 1837-38 $\left(1^{\circ}\right.$ \& $2^{\circ}$ VICTORIAE) arranged in fifty-one volumes. Vol. XXXIII. London.

Bloor, David (2007): Ideals and Monisms: Recent Criticisms of the Strong Programme in the Sociology of Knowledge. Studies In History and Philosophy of Science Part A. 38(1):210-234.

Brock, William H. and Meadows, Arthur J. (1998): The Lamp of Learning: Two Centuries of Publishing at Taylor and Francis. $2^{\text {nd }}$ ed. London: Taylor and Francis.

Buzelin, Hélène (2005): Unexpected Allies: How Latour's Network Theory Could Complement Bourdieusian Analyses in Translation Studies. The Translator. 11(2):193-218.

Buzelin, Hélène (2006): Independent Publisher in the Networks of Translation. TTR: traduction, terminologie, rédaction. 19(1):135-173.

Buzelin, Hélène (2007): Translations 'in the Making.' In: Michaela Wolf and Alexandra FukARI, eds. Constructing a Sociology of Translation. Amsterdam/Philadelphia: John Benjamins, 135-169.

Collins, Harry M. and Evans, Robert (2002): The Third Wave of Science Studies: Studies of Expertise and Experience. Social Studies of Science. 32(2):235-296.

Fox Keller, Evelyn (1985): Reflections on Gender and Science. New Haven: Yale University Press. Fuegi, John and Francis, Jo (2003): Lovelace and Babbage and the Creation of the 1843 'Notes.' IEEE Annals of the History of Computing. 25(4):16-26.

Gouanvic, Jean-Marc (2005): A Bourdieusian Theory of Translation, or the Coincidence of Practical Instances: Field, 'Habitus,' Capital and 'Illusio.' The Translator. 11(2):147-166. 
Green, Christopher D. (2001): Charles Babbage, the Analytical Engine, and the Possibility of a 19th-Century Cognitive Science. In: Christopher D. Green, Marlene Shore and Thomas Teo, eds. The Transformation of Psychology: Influences of 19th-Century Philosophy, Technology, and Natural Science. Washington: American Psychological Association, 133-152.

Hammersley, Martyn and Atrinson, Paul (2007): Ethnography: Principles in Practice. $3^{\text {rd }}$ ed. London/New York: Routledge.

Haraway, Donna (1988): Situated Knowledges: The Science Question in Feminism as a Site of Discourse on the Privilege of Partial Perspective. Feminist Studies. 14(3):575-599.

Haraway, Donna (1991): Simians, Cyborgs, and Women: The Reinvention of Nature. London/ New York: Routledge.

Hermans, Theo (2007): The Conference of the Tongues. Manchester: St. Jerome.

Huskey, Velma R. and Huskey, Harry D. (1980): Lady Lovelace and Charles Babbage. Annals of the History of Computing. 2(4):299-329.

InghILleri, Moira, ed. (2005): The Translator, Special Issue on Bourdieu and the Sociology of Translation and Interpreting. 11(2).

Jardine, Nick (2000): The Scenes of Inquiry: On the Reality of Questions in the Sciences. $2^{\text {nd }}$ ed. Oxford: Oxford University Press.

Karamanis, Nikiforos, Luz, Saturnino and Doherty, Gavin (2011): Translation Practice in the Workplace: Contextual Analysis and Implications for Machine Translation. Machine Translation. 25(1):35-52.

Kinnunen, Tuija and Koskinen, Kaisa, eds. (2010): Translators' Agency. Tampere: Tampere University Press.

Knight, David (1986): The Age of Science: The Scientific World-View in the Nineteenth Century. Oxford: Basil Blackwell.

Knorr Cetina, Karin (1999): Epistemic Cultures: How the Sciences make Knowledge. Cambridge: Harvard University Press.

Knorr Cetina, Karin (2001): Laboratory Studies: Historical Perspectives. In: Neil J. Smelser and Paul B. BALtes, eds. International Encyclopedia of the Social and Behavioral Sciences. Oxford: Pergamon, 8232-8238.

Knorr Cetina, Karin (2007): Culture in Global Knowledge Societies: Knowledge Cultures and Epistemic Cultures. Interdisciplinary Science Reviews. 32(4):361-375.

Koskinen, Kaisa (2008): Translating Institutions: An Ethnographic Study of EU Translation. Manchester: St. Jerome.

Kunn, Thomas S. (1962): The Structure of Scientific Revolutions. $1^{\text {st }}$ ed. Chicago: University of Chicago Press.

Kunn, Thomas S. (1970): The Structure of Scientific Revolutions. $2^{\text {nd }}$ ed. Chicago: University of Chicago Press.

Latour, Bruno (2005): Reassembling the Social: An Introduction to Actor-Network-Theory. Oxford: Oxford University Press.

Latour, Bruno and Woolgar, Steve (1979): Laboratory Life: The Social Construction of Scientific Facts. $1^{\text {st }}$ ed. Beverly Hills: Sage.

Latour, Bruno and Woolgar, Steve (1986): Laboratory Life: The Construction of Scientific Facts. $2^{\text {nd }}$ ed. Princeton: Princeton University Press.

LAW, John (1992): Notes on the Theory of the Actor-Network: Ordering, Strategy, and Heterogeneity. Systemic Practice and Action Research. 5(4):379-393.

Leblanc, Matthieu (2013): Translators on Translation Memory (TM): Results of an Ethnographic Study in Three Translation Services and Agencies. Translation and Interpreting. 5(2):1-13.

Luff, Paul, Hindmarsh, Jon and Heath, Christian, eds. (2000): Workplace Studies: Recovering Work Practice and Informing System Design. Cambridge: Cambridge University Press.

Mcdonough Dolmaya, Julie (2012): Analyzing the Crowdsourcing Model and its Impact on Public Perceptions of Translation. The Translator. 18(2):167-191.

Merton, Robert K. (1973): The Sociology of Science: Theoretical and Empirical Investigations. Chicago: University of Chicago Press. 
Milton, John and Bandia, Paul, eds. (2009): Agents of Translation. Amsterdam/Philadelphia: John Benjamins.

Mossop, Brian (2000): The Workplace Procedures of Professional Translators. In: Andrew Chesterman, Natividad Gallardo San Salvador and Yves Gambier, eds. Translation in Context. Amsterdam/Philadelphia: John Benjamins, 39-48.

Mossop, Brian (2006): From Culture to Business: Federal Government Translation in Canada. The Translator. 12(1):1-28.

Olohan, Maeve (2011): Translators and Translation Technology: The Dance of Agency. Translation Studies. 4(3):342-357.

Olohan, Maeve (2012): Volunteer Translation and Altruism in the Context of a NineteenthCentury Scientific Journal. The Translator. 18(2):193-215.

Olohan, Maeve (2014): Gate-keeping and Localizing in Scientific Translation Publishing: The Case of Richard Taylor and Scientific Memoirs. The British Journal for the History of Science. 47(3):433-450.

Olohan, Maeve and Davitti, Elena (2015): Dynamics of Trusting in Translation Project Management: Leaps of Faith and Balancing Acts. Journal of Contemporary Ethnography. Online 4 october 2015, <doi:10.1177/0891241615603449>.

Olohan, Maeve and Salama-CARr, Myriam, eds. (2011): The Translator, Special Issue on Science in Translation. 17(2).

OrLikowski, Wanda J. (2005): Material Works: Exploring the Situated Entanglement of Technological Performativity and Human Agency. Scandinavian Journal of Information Systems. 17(1):183-186.

Pérez González, Luis (2010): 'Ad-hocracies' of Translation Activities in the Blogosphere: A Genealogical Case Study. In: Mona Baker, Maeve Olohan and María Calzada Pérez, eds. Text and Context: Essays on Translation and Interpreting in Honour of Ian Mason. Manchester: St. Jerome, 259-287.

Pérez González, Luis (2013): Amateur Subtitling as Immaterial Labour in Digital Media Culture: An Emerging Paradigm of Civic Engagement. Convergence: The International Journal of Research into New Media Technologies. 19(2):157-175.

Pickering, Andrew (1984): Constructing Quarks: A Sociological History of Particle Physics. Chicago: University of Chicago Press.

Pickering, Andrew (1992): From Science as Knowledge to Science as Practice. In: Andrew Pickering, ed. Science as Practice and Culture. Chicago: University of Chicago Press, 1-28.

Pickering, Andrew (1993): The Mangle of Practice: Agency and Emergence in the Sociology of Science. The American Journal of Sociology. 99(3):559-589.

Pickering, Andrew (1995): The Mangle of Practice: Time, Agency, and Science. Chicago: University of Chicago Press.

Pickering, Andrew (2003): On Becoming: Imagination, Metaphysics, and the Mangle. In: Don IHde and Evan Selinger, eds. Chasing Technoscience: Matrix for Materiality. Bloomington: Indiana University Press, 96-116.

Pickering, Andrew (2008a): New Ontologies. In: Andrew Pickering and Keith Guzik, eds. The Mangle in Practice: Science, Society and Becoming. Durham: Duke University Press, 1-14.

Pickering, Andrew (2008b): Preface. In: Andrew Pickering and Keith Guzik, eds. The Mangle in Practice: Science, Society and Becoming. Durham: Duke University Press, vii-xiv.

Pickering, Andrew (2010): The Cybernetic Brain: Sketches of Another Future. Chicago: University of Chicago Press.

Pickering, Andrew and Guzik, Keith, eds. (2008): The Mangle in Practice: Science, Society and Becoming. Durham: Duke University Press.

Shapin, Steven (1988): Following Scientists around. Social Studies of Science. 18:533-550.

Simeoni, Daniel (1998): The Pivotal Status of the Translator's Habitus. Target. 10(1):1-39.

Sismondo, Sergio (2010): An Introduction to Science and Technology Studies. $2^{\text {nd }}$ ed. Chichester: John Wiley and Sons. 
Storer, Norman W. (1973): Introduction. In: Robert K. Merton. The Sociology of Science: Theoretical and Empirical Investigations. Chicago: University of Chicago Press, xi-xxxi.

Toole, Betty A. (1996): Ada Byron, Lady Lovelace, an Analyst and Metaphysician. IEEE Annals of the History of Computing. 18(3):4-12.

Topham, Jonathan R. (2004): Technicians of Print and the Making of Natural Knowledge. Studies in History and Philosophy of Science. 35(2):391-400.

Traweek, Sharon (1988): Beamtimes and Lifetimes: The World of High Energy Physicists. Cambridge: Harvard University Press.

Tyulenev, Sergey (2012): Applying Luhmann to Translation Studies: Translation in Society. London/New York: Routledge.

Zammito, John (2007): What's 'New' in the Sociology of Knowledge? In: Stephen P. Turner and Mark W. Risjord, eds. Philosophy of Anthropology and Sociology. Amsterdam: NorthHolland, 791-857. 